\title{
A Cuban NGO Perspective on Disabilities: José Blanch MD MPH President, National Association of Blind Persons
}

\author{
By Gail Reed MS
}

Dual specialties in epidemiology and labor medicine, as well as an advanced degree in public health, gave Dr José Blanch expertise on disabilities in Cuba from a population health perspective. However, when he began losing his sight due to a diabetic retinopathy while serving in Africa, he also began a difficult journey that would transform his life and career, giving him new personal and professional perspectives on disability and the potential of disabled persons. Active for the past several years in the National Association of Blind Persons (ANCl, its Spanish acronym), in 2010 Dr Blanch was elected President of the non-governmental organization. He spoke with MEDICC Review about ANCl's role and challenges in the context of Cuba today.

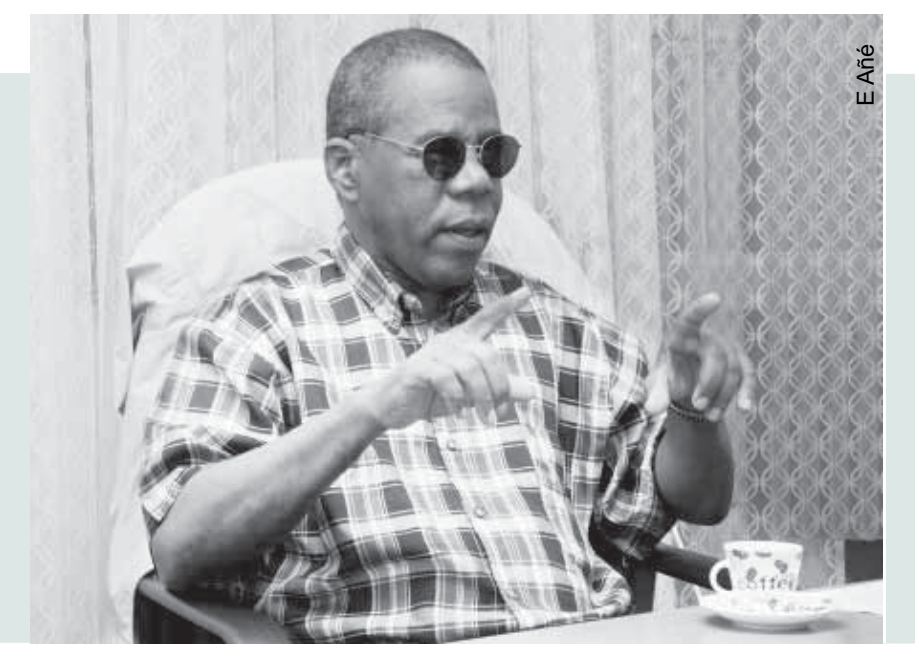

MEDICC Review: First, tell us a bit about ANCI itself, its membership, history and how its work has evolved over time.

José Blanch: ANCl was founded in 1975 as a non-governmental organization. The idea was to bring together persons who were visually disabled-either blind or with low vision-in the struggle to promote all actions contributing to their fullest rehabilitation and integration into society.

This is still our mission today, and our work takes us into the fields of rehabilitation, sports, education, the arts, computer sciences, and job training, among others. We also aim to educate the general public about disabilities and raise awareness of the needs, potential and aspirations of blind and visually impaired people.

Two major institutions come under our purview: the National Center for Culture and Recreation and the National Rehabilitation Center for visually-disabled persons. The first includes a central library with specialized services for blind and low-vision users; a publishing house that produces several titles annually, plus our own ANCI magazine and bulletin; a teaching arm for learning the basic computer sciences so vital today; and cultural extension programs to develop the artistic vocation and talents of our members.

The Rehabilitation Center, opened in 1990 with assistance from the Norwegian Blind Association, offers 33 courses for blind persons, each lasting several months. These include movement and orientation, Braille reading and writing, abacus management for math, typing and paper-and-ink writing, daily-life activities, music, and exercises; plus computer sciences and other useful skills such as carpentry, ceramics, plumbing, and gardening. Some 1500 Cuban and 70 international students have completed studies at the Center, enhancing their rehabilitation and broadening their opportunities.

Today, we have 32,000 active members throughout the countrywith the highest membership in Santiago de Cuba, Havana and Holguin provinces, in that order.
We receive public funding and also assistance from international partners; we are founders of the Latin American Union of Blind Persons and members of the World Union of the Blind.

MEDICC Review: What are the barriers facing Cubans who have low vision or are blind?

José Blanch: We have come a long way, but there is much to be done: barriers are not only architectural, potholes in the streets or buildings without easy access. They can also be bureaucratic, technological, and above all psychological. Sometimes it's a matter of people not being sensitive enough to the small things that can make a big difference for the fulfillment, development and independence of people with disabilities, including those of us who are visually impaired. It is also important for people with disabilities to know their rights and the legal and social protections they are entitled to.

A lot has been done to raise the profile of disabled persons in sports, giving full television coverage to the Special Olympics for example. I think that this has made people realize how much a person with disabilities is capable of doing. Technology is helping to overcome communications barriers all the time-computers an essential part of that process. Little by little, more is being done in other areas, too, such as urban planning.

But the main problem is still cultural, generating a deeper understanding in the general public about the real needs and potential of people with disabilities. The mass media could do much more: for example, individuals who are disabled appear rarely on television, even in fictional series; and on TV, you've certainly never seen a blind physical therapist using massage to alleviate a patient's pain.

MEDICC Review: Does ANCI play any role in policy formulation to address these and other issues?

José Blanch: Yes, for example in the National Commission for Attention to Persons with Disabilities (CONAPED), which involves 
high-level representatives from all ministries and sectors responsible for designing and coordinating a national action plan to address the needs and concerns of disabled persons. Led by the Ministry of Labor and Social Security, CONAPED includes the ministries of Public Health, Education, Higher Education, Communications, Culture, and Justice, among others, as well as the Sports and Housing Institutes. CONAPED has branches at the provincial and municipal levels in addition to its national council.

$\mathrm{ANCl}$ acts as a civil-society counterpart to the Commission: we attend its meetings, raising critiques and offering suggestions on problems and issues that we believe need attention. Similar associations of persons with other kinds of disabilities play the same role in CONAPED.

There are dozens of examples where our voice has made a difference-for example in protecting the jobs of visually disabled persons in the trades' shops organized by the Ministry of Light Industry. We have also proposed new legislation to Parliament, a new bill on disabilities that we believe is important, since it is intended to integrate the various ministerial resolutions that explicitly protect the rights of disabled persons. That bill is now under consideration in parliamentary committee, and we will be consulted again before its final version goes to the floor. Another bill we have supported is expected to come before the whole parliament even sooner, devoted to improving accessibility for disabled persons-especially important for blind and visually impaired people.

MEDICC Review: What about economic and social protection for disabled persons, given the impending layoffs of public workers and other budget cuts?

José Blanch: Many protections are already guaranteed under the constitution, such as health care and education. Others are covered by regulations already in place, particularly concerning social security. But, as I said, now we are advocating a more comprehensive law on disabilities.

Concerning the current reorganization of the labor force, we suggested special provisions be included prohibiting layoffs of disabled persons from the kind of shops I mentioned earlier, and we are glad to see that these are now in place. Perhaps we will also see opportunities to convert some of these shops into cooperatives as well, with certain guarantees by government.

Other provisions and options are still under discussion, including the extent of government responsibility for those disabled persons who can work, which should also be addressed in the new law being formulated.

MEDICC Review: Do you have particular approaches for women, older adults, young people, or other groups within the organization?

José Blanch: First, it's interesting to note that in Cuba, the rates of blindness have decreased over the last few decades in relation to low vision, given that we rarely see vision loss due to infection, as happens frequently in many developing countries. Our vision loss has much more to do with congenital or noncommunicable chronic conditions and with aging in particular: cataracts, for example, are the number one cause of vision loss in Cuba, followed by glaucoma.
Given that Cuban society as a whole is also aging at a fast rate, this means that older adults are a priority for $\mathrm{ANCl}$. In fact, they are $45 \%$ of our membership — that is, 14,500 of us are over 60 years old —and much of our leadership is older as well. Our challenge is to see to it that the growing demands of these people are effectively met. We have strong ties to seniors' clubs; to the municipal Labor, Social Security and Assistance departments that oversee nursing homes and other services; and social workers are involved with us at the local level. I think one of the most important initiatives recently has been incorporation of our members into the University for Older Adults, with classrooms around the country that stimulate their intellectual involvement.

\begin{tabular}{l|r|}
\hline ANCI Membership, 2010 & 7155 \\
\hline Blind & 24,380 \\
\hline Low vision & 733 \\
\hline Sighted & 32,268 \\
\hline Total members & 1498 \\
\hline Associate members (<14 years) & 33,766 \\
\hline Total
\end{tabular}

Source: ANCI, Havana.

Our work with young people is weaker. Our challenge is to motivate them to join $\mathrm{ANCl}$, even when they are involved in inclusive programs within the broader Cuban education system that tend to diminish stigma and feelings of 'otherness.' Many of them have transitioned from schools for children with special needs into the regular public school system. The trend is such that some provinces now only have primary schools for children with special needs, after which students graduate into the regular secondary and high schools. So our challenge is to stay in touch with these students, and ensure that their social inclusion doesn't mean distancing themselves from $\mathrm{ANCl}$, an organization with an important role to play in advising policy decisions that affect blind and visually impaired individuals, including these young people. Right now, only about $11 \%$ of our membership (583 blind and 2718 with low vision) is composed of young people over 17 years old. Until now, before that age, while they usually belong to the general student organizations, they are only involved in $\mathrm{ANCl}$ as associate members.

Women constitute some $42 \%$ of our membership, a total of 13,708 (2852 blind and 10,856 with low vision). Two-thirds of them have completed courses at rehabilitation centers, and $27 \%$ are either studying or working outside the home. Some 470 are involved in the organization's leadership in some capacity, and we now have an $\mathrm{ANCl}$ commission devoted to gender equity.

\section{MEDICC Review: What are the main challenges ahead for ANCI members and disabled persons in Cuba today?}

José Blanch: Our main challenges are common to Cuba as a whole, and they are economic. But in our case, we have the added challenge in this context of recognizing our potential, and also having others recognize it as well. Sometimes people will actually congratulate me on International Day of Persons with Disabilities...I always tell them, 'Don't congratulate me for being disabled! Congratulate me instead for what I am able to do!'

If each of us is to secure a fulfilling place in this society, then we must be thought of as people first, and then and only then, as individuals who happen to be disabled.

This means strengthening our organization at every level. - - / - 